\title{
The Impact of the Techniques and Tactics Appropriate by the Athletes in Phase Triple Jump and Their Relationships with the Finale Results
}

\author{
Zerf Mohammed, Mokkedes Moulay Idriss, Bengoua Ali, Bendahmane Med Nasreddin and Guebli Abd-el-Kader \\ Physical Education Institute Laboratory OPAPS, University Abdel Hamid Ibn Badis Mostaganem, Mostaganem 27000, Algeria
}

\begin{abstract}
The purposes of this study were to describe and compare the techniques used by elite world triple jumper and the Algerian elite team to determine the impact of distribution modality phases allowing the elite to exceeds 17-meter. Our subjects were two world elite 2009 and two Algerian national elite 2013. In the lack of new technology Modern measuring instruments kinematics or kinetics, our study based in measure of the Phase distribution ratio as measure of Stride length Jump distance. That literature review two schools, the Russian technique (which emphasizes the hop phase) and the Polish technique (which emphasizes the jump phase). Our aims for this study are: Are there any statistically significant differences between the results of the samples in the distance achieved? Are there any statistically significant differences between practical Ratio relative distances (world 2009-national 2013)? Are there any statistically significant differences between Stride length phase distances (world 2009-national 2013)? For that, we have chosen the analysis of variance and correlation of the distances achieved in each of the phases with the official distance of jumper and "T" student to compare implementation distribution of phases (hop, step and jump) with the results accuses. Based on the practices and weaknesses of elites in practice, we confirm: (1) All the samples practice the Russian technique as model in the distribution of the phase ratio; (2) The problem of our elites is in the hop phase distribution and its relationship with other phases; (3) Improve achieve horizontal vertical velocity in hop phase as solution.
\end{abstract}

Key words: The ratio phase, techniques, tactics appropriate, triple jump.

\section{Introduction}

The original triple jump as practiced by the Greeks was no more than three long jumps. The regulated triple jump was protected at the end of the XIX century, first by the Irish and then by the Americans [1].

The triple jump was inspired by the ancient Olympic Games and has been a modern Olympics event since the Games' inception in 1896. According to IAAF (International Association of Athletics Federations) rules, the hop shall be made so that an athlete lands first on the same foot as that from which he has taken off in the step, he shall land on the other foot, from which, subsequently, the jump is performed

Corresponding author: Zerf Mohammed, Ph.D., research field: biomechanics sports evaluation training. E-mail: biomeca.zerf@outlook.com
[2]. The current male and female world record holders are Jonathan Edwards of Great Britain, with a jump of $18.29 \mathrm{~m} \mathrm{(60} \mathrm{ft.} 0$ in), and Inessa Kravets of Ukraine, with a jump of $15.50 \mathrm{~m}$ (50 ft. $10 \mathrm{in})$. Both records were set during 1995 World Championships in Gothenburg.

The current record male Africa $17.37 \mathrm{~m}(56 \mathrm{ft}$. $113 / 4$ in) by Tarik Bouguetaïb (MAR) and female is $15.39 \mathrm{~m}$ (50 ft. 53/4 in) Françoise Mbango Etone (CMR).

The best record of Algerian female is $14.98 \mathrm{~m} \mathrm{(+}$ $0.2 \mathrm{~m} / \mathrm{s}$ ) By Baya Rahouli in Meeting Almeria 1 Juliet 2005 the best record of male Algerian is $16.92 \mathrm{~m}$ by Lotfi Khaïda Monaco Herculis games in August 7, 1993 [3].

The literature review reveals that the triple jump consists of a running approach, 3 take-off phases in which the athlete hops on one foot, lands on the same 
foot, steps onto the opposite foot, and finally jumps and lands in the sand pit [4].

The lengths of the three phases are typically about $39 \%, 30 \%, 31 \%$ of the total length of the jump for the Russian technique, and 35\%,29\%, 36\% of the total length for the Polish technique [5]. Allen et al. reported that the world record performances from 1911 to 1985 a move away from a hop-dominated technique with a small step phase (40-41\%:22\%:36-38\%), towards a hop-dominated technique with a larger step phase (37-39\%:28-30\%:31-33\%), and latterly towards a jump-dominated technique (34-35\%:28-30\%:36-37\%) [6].

Hiu confirmed that Phase ratio is a measure of effort distribution in the triple jump [7]. Hop-dominant, balanced, and jump-dominant techniques were three triple jump techniques defined based on phase ratio.

For the reason that our elites does not exceed 17-meter, our goal is to introduce the biomechanics evaluation before explaining the reason scientific of the absence of the Algerian performance elite in world festivals by discussing the importance of maintaining the model distribution ratios applied in the outcome.

In addition, our research analyzed the performance of Algerian elites as first part and the second part was to compare their results with the world's elite 2009 to illustrate the importance of the good contribution of the phase jump on the results. Our motive is to highlight the biomechanical assessment for Algerian coaches to plan the choice of the right assessment technique to their athletes.

\section{Material and Methods}

For the purposes of analysis, we have calculated the distance of the hop phase (the distance of the hop), and step phase (the distance of the step), and the phase jump (the distance of the jump), in two-dimensional [8].

The analysis of the present study was with the software Kinovea, the capture and measured distance of each phase of triple jump as Fig.1.

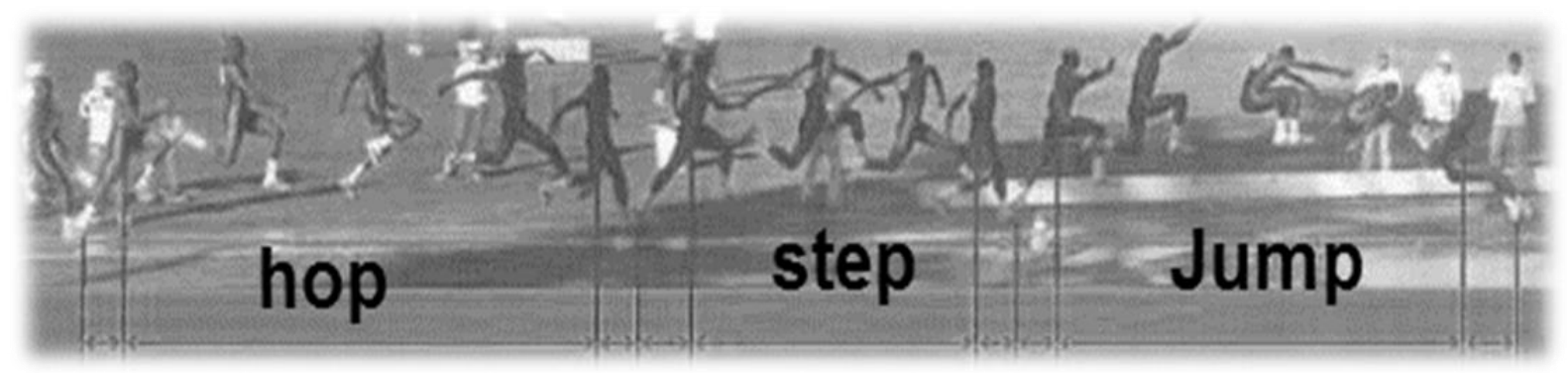

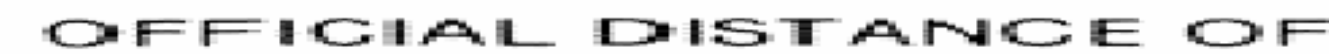 TRIPLE JUNAP}

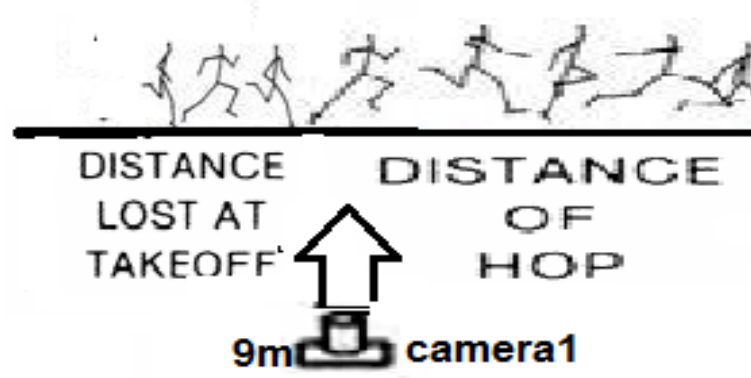

Fig. 1 The method chosen to calculate the Distance of phase [9]. 
Sites of the three cameras that depicting the distance triple jump

These cameras were placed at distances of $19.4 \mathrm{~m}$ and $22.1 \mathrm{~m}$ from the midline of the triple jump runway, with their optical axes at right angles to this line. The first camera was placed $0.9 \mathrm{~m}$ forward (or on the pit side) of the front edge of the board and was used to record the subjects' performances during the hop phase of the triple jump. The second camera was placed $13.0 \mathrm{~m}$ forward of the front edge of the board and was used to record performances during the step and jump phases [8]. To measure the real distance, a series of markers was placed in carefully measured locations along the inside, curb of the track between the runway and each camera. These markers served as reference measurement.

\section{Data Collection}

\subsection{Subjects}

The subjects were the two-world champions Berlin 2009 results from the German athletics federation [10] and for Algerian; we have made analyses of their performances in similar study [11].

\subsection{Data Reduction}

Our cameras were attached to our laptops to record directly into folders prepare in advance for each subject chosen for analysis. The distances of the analyses tests are shown in Table1 (a-b) for all the subjects and Table 1(b) for Algerian elite's team. With the software Kinovea, the films obtained for each test were phase analysis for each variable and participant.

\subsection{Data Analysis}

The data analysis procedures used in this study consisted of the computation of the means, standard deviations, the Pearson correlations and Independent Samples Test of all the variables identified in based of the theoretical model in the similar studies (Fig. 1).

\section{Results}

From Table 2, through the results of the paired $\mathrm{T}$ student and Pearson correlation at the 0.05 level (2-tailed) and Degrees of freedom (n-1) are not significant at the 0.01 level (2-tailed) in all comparisons except in the hop phase.

\section{Conclusion}

From this, we conclude that the tactics appropriate used by nationalist elements remain far from the level of application of the Champions world within this technique (which emphasizes the hop phase) in hop phase comparison.

Table 1 (a-b) Description of The Acquired Results of Our Samples.

\begin{tabular}{|c|c|c|c|c|}
\hline \multicolumn{5}{|c|}{ The Results (a) Champions World 2009 [10] } \\
\hline \multirow{2}{*}{ Variables } & \multirow{2}{*}{$\begin{array}{l}\text { Real } \\
\text { Distance }\end{array}$} & \multicolumn{3}{|c|}{ Stride length $(\mathrm{m})$} \\
\hline & & Hop & Step & Jump \\
\hline World Champion & 17.92 & 6.49 & 5.41 & 6.02 \\
\hline Vice World & 17.60 & 6.51 & 5.41 & 5.68 \\
\hline Mean & 17.76 & 6.50 & 5.41 & 5.85 \\
\hline $\mathrm{SD}$ & 0.23 & 0.01 & 0.00 & 0.24 \\
\hline \multicolumn{5}{|c|}{ The Results (b) Algerian Champions 2013 after the kinematics analysis [11] } \\
\hline \multirow{2}{*}{ Variables } & Real & \multicolumn{3}{|c|}{ Stride length (m) } \\
\hline & Distance & Hop & Step & Jump \\
\hline Champion Algeria & 16.16 & 5.79 & 5.1 & 5.27 \\
\hline Vice Champion & 16.15 & 5.72 & 5.02 & 5.41 \\
\hline Mean & 16.16 & 5.76 & 5.06 & 5.34 \\
\hline SD & 0.01 & 0.05 & 0.06 & 0.10 \\
\hline
\end{tabular}


Table 2 Deference statistical existed between the results of the samples obtained in the final distance.

\begin{tabular}{|c|c|c|c|c|c|c|c|}
\hline variables & & Mean & SD & $\mathrm{t}$ & df & $\mathrm{R}$ & Sig. (2-tailed) \\
\hline \multirow{2}{*}{ Total distance } & World & 17.76 & 0.23 & \multirow{2}{*}{10.36} & & \multirow{2}{*}{+1} & \multirow{2}{*}{0.06} \\
\hline & Algerian & 16.16 & 0.01 & & & & \\
\hline \multirow{2}{*}{ Hop } & World & 6.50 & 0.014 & \multirow{2}{*}{16.56} & & \multirow{2}{*}{-1} & \multirow{2}{*}{0.038} \\
\hline & Algerian & 5.76 & 0.049 & & 01 & & \\
\hline \multirow{2}{*}{ Step } & World & 5.41 & 0.00 & \multirow{2}{*}{8.87} & 01 & \multirow{2}{*}{+1} & \multirow{2}{*}{0.071} \\
\hline & Algerian & 5.06 & 0.06 & & & & \\
\hline \multirow{2}{*}{ Jump } & World & 5.85 & 0.24 & \multirow{2}{*}{2.13} & & \multirow{2}{*}{-1} & \multirow{2}{*}{0.280} \\
\hline & Algerian & 5.34 & 0.09 & & & & \\
\hline
\end{tabular}

Table 3 The connectivity relationships between variables in order to study.

\begin{tabular}{lllll}
\hline \multicolumn{2}{l}{ Correlations length phase distance for our samples } & & & Jump \\
\hline variables & & Hop & Step & $0.869^{*}$ \\
\multirow{3}{*}{ Hop } & Pearson Correlation & 1 & $0.995^{* *}$ & 0.131 \\
& Sig. (2-tailed) & & 0.005 & 4 \\
\hline \multirow{3}{*}{ Step } & $\mathrm{N}$ & 4 & 4 & $0.852^{*}$ \\
& Pearson Correlation & $0.995^{* *}$ & 1 & 0.148 \\
& Sig. (2-tailed) & 0.005 & & 4 \\
\multirow{2}{*}{ Jump } & $\mathrm{N}$ & 4 & 4 & 1 \\
& Pearson Correlation & $0.869^{*}$ & $0.852^{*}$ & 4 \\
\end{tabular}

** Correlation is significant at the 0.01 level (2-tailed).

From Table 3, through the results of correlations length phase distance for our samples at the 0.01 level (2-tailed) and degrees of freedom $(n=4)$, the correlations is strong positive significant in all the comparisons except in the jump phase.

Since the differences are not statistically significant, all our samples practice the Russian technique (which emphasizes the hop phase).

From the Table 4 (a), through the results of the mean of the Ratio World Jumpers, we conclude that the dominant techniques is for the benefit of the Hop-dominated technique with a length of three phases are typically $(36 \%, 31 \%, 33 \%)$. Based on the results obtained, we referred to the practice of the Russian technique (emphasizes the hop phase) $[9,12$, 13].

Table 4 (b) shows the results of the correlations of the ratio based on the relative distance for our champion world. The simple correlation is significant positive at the 0.01 level (2-tailed) in all comparisons, except in the jump phase which is strong negative.
From that, we confirm that the dominant techniques is in the benefit of the Hop-dominated. Based on the results obtained, we referred to the practice of the Russian technique (emphasizes the hop phase) $[9,12$, 13].

Table 4 (c) shows the results of the mean of the Ratio Algerians Jumpers, and we conclude that the dominant techniques is for the benefit of the Hop-dominated technique

Table 4 (d) shows the results of the correlations of the ratio based on the relative distance of the Algerian Champion 2013, the simple correlation is significant positive at the 0.01 level (2-tailed) in all comparisons, except in the jump phase which is strong negative; we confirm that the dominant technique is in the benefit of the Hop-dominated. Based on the results obtained, we referred to the practice of the Russian technique (emphasizes the hop phase) $[9,12,13]$.

Table 5 (a) shows the results of the Independent Samples Test for the Stride length phase distance between our champions (world-national), which is 
Table 4 (a) The practical ratio relative distance for the World Champion 2009.

\begin{tabular}{lllll}
\hline \multicolumn{2}{l}{ (a) Champion World 2009 based on the relative distance (\%) } \\
\hline \multirow{2}{*}{ Variables } & \multicolumn{3}{l}{ Jump } & \multicolumn{1}{l}{ Relative Distance (\%) } \\
\cline { 2 - 5 } & Distance (m) & Hop Ratio (\%) & Step Ratio (\%) & Jump Ratio (\%) \\
\hline World champion & 17.92 & 36.22 & 30.19 & 33.59 \\
Vice World & 17.60 & 36.99 & 30.74 & 32.27 \\
Mean & 16.96 & 36.60 & 30.46 & 32.93 \\
SD & 0.94 & 0.55 & 0.39 & 0.93 \\
\hline
\end{tabular}

Table 4 (b) The correlations on the relative distance phase for the World Champion 2009.

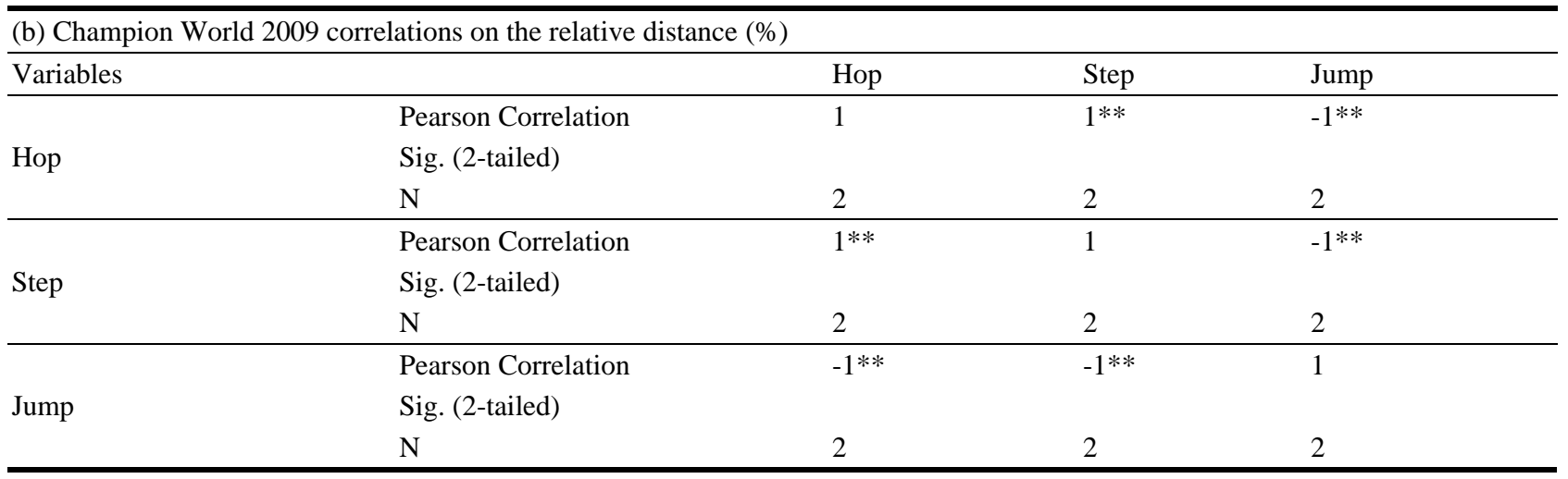

** Correlation is significant at the 0.01 level (2-tailed).

Table 4 (c) The practical ratio relative distance for the Algerian Champions 2013.

\begin{tabular}{lllll}
\hline (c) Algerian Champions & \multicolumn{2}{l}{ 2013 based on the relative distance (\%) } & & \\
\hline Variables & Distance $(\mathrm{m})$ & Hop ratio $(\%)$ & Step ratio (\%) & Jump ratio (\%) \\
World champion & 16.16 & 35.83 & 31.56 & 32.61 \\
Vice world & 16.15 & 35.42 & 31.08 & 33.50 \\
Mean & 16.155 & 35.62 & 31.32 & 33.05 \\
SD & 0.01 & 0.29 & 0.34 & 0.63 \\
\hline
\end{tabular}

Table 4 (d) The correlations on the relative distance phase for the Algerian Champion 2013.

\begin{tabular}{|c|c|c|c|c|}
\hline Variables & & Hop & Step & Jump \\
\hline & Pearson Correlation & 1 & $1 * *$ & $-1 * *$ \\
\hline \multirow[t]{3}{*}{ Hop } & Sig. (2-tailed) & & & \\
\hline & $\mathrm{N}$ & 2 & 2 & 2 \\
\hline & Pearson Correlation & $1 * *$ & 1 & $-1 * *$ \\
\hline \multirow[t]{3}{*}{ Step } & Sig. (2-tailed) & & & \\
\hline & $\mathrm{N}$ & 2 & 2 & 2 \\
\hline & Pearson Correlation & $-1 * *$ & $-1 * *$ & 1 \\
\hline \multirow[t]{2}{*}{ Jump } & Sig. (2-tailed) & & & \\
\hline & $\mathrm{N}$ & 2 & 2 & 2 \\
\hline
\end{tabular}

** Correlation is significant at the 0.01 level (2-tailed).

significant at the 0.05 level (2-tailed) in all comparisons, except in jump phase. From that, we confirm the superiority hurt in the interest of world champions in phases (hop and step).
Table 5 (b) show the results of the correlations the Stride length phase distance between our champions (world-national), which is significant at the 0.01 level (2-tailed) in all comparisons, except in correlations 
Table 5 (a) Independent samples test of the stride length phase distance between our champions (world-national).

\begin{tabular}{|c|c|c|c|c|c|c|}
\hline \multicolumn{2}{|c|}{ Independent Samples Test } & $\mathrm{M}$ & SD & $\mathrm{T}$ & $\mathrm{df}$ & Sig. (2-tailed) \\
\hline \multirow{2}{*}{ Hop } & World & 6.50 & 0.015 & \multirow{2}{*}{20.467} & & \multirow{2}{*}{0.002} \\
\hline & Algerian & 5.76 & 0.049 & & & \\
\hline \multirow{2}{*}{ Step } & World & 5.41 & 0.00 & \multirow{2}{*}{8.750} & 2 & \multirow{2}{*}{0.013} \\
\hline & Algerian & 5.06 & 0.056 & & 2 & \\
\hline \multirow{2}{*}{ Jump } & World & 5.85 & 0.24 & \multirow{2}{*}{2.774} & & \multirow{2}{*}{0.109} \\
\hline & Algerian & 5.34 & 0.099 & & & \\
\hline
\end{tabular}

Table 5 (b) Correlations of the stride length phase distance between our champions (world-national).

\begin{tabular}{|c|c|c|c|c|}
\hline \multicolumn{5}{|c|}{ (b) Correlations the Stride length phase distance } \\
\hline variables & & Hop ALG & Step ALG & Jump ALG \\
\hline \multirow[t]{2}{*}{ Hop CW } & $\begin{array}{l}\text { Pearson Correlation } \\
\text { Sig. (2-tailed) }\end{array}$ & $-1 * *$ & $-1 * *$ & $1 * *$ \\
\hline & $\mathrm{N}$ & 2 & 2 & 2 \\
\hline \multirow[t]{2}{*}{ Step CW } & $\begin{array}{l}\text { Pearson Correlation } \\
\text { Sig. (2-tailed) }\end{array}$ & $1 * *$ & $1 * *$ & $-1 * *$ \\
\hline & $\mathrm{N}$ & 2 & 2 & 2 \\
\hline \multirow[t]{2}{*}{ Jump CW } & $\begin{array}{l}\text { Pearson Correlation } \\
\text { Sig. (2-tailed) }\end{array}$ & $1 * *$ & $1 * *$ & $-1 * *$ \\
\hline & $\mathrm{N}$ & 2 & 2 & 2 \\
\hline
\end{tabular}

** Correlation is significant at the 0.01 level (2-tailed).

phase (hop (CW)*hop (Alg), hop (CW)* step (ALG),step(CW)*jump(ALG) and jump (CW)-jump (ALG)). Based on the synthesis of Ed Jacoby [14] , the triple jump good coach understands that good mechanics in the transition phases leads to a good performance and that any error in any phase will be related to another. For this reason, we confirm that the strength of our world champions is in the correct practice of this technique that requires good mechanical and physical control in the transition between phases.

\section{Discussion}

The study showed that the Russian technique (which emphasizes the hop phase) most used by our samples was the technique hop. The most difference between the world champions and our elites are in hop phase. Paul [15] explained the objective of this phase is to achieve horizontal vertical velocity (going forward and up) of the takeoff board, not vertical horizontal velocity (up and forward as in the long jump) and any change should minimally in the step phase change the angular momentum created by hop [16].

For our research, we explain that difference in the level of optimum phase practiced by our champion world in the transition of the advantage hop phase that any error in achieve horizontal vertical velocity are related in the other phases. For that, we advise our coach and their elites the recommendation of $\mathrm{K}$. Dziewiecki, Z. Mazur [17] . The phase's ratios distances must be learned measured and practiced as effort distribution in their techniques (Hop-dominant, balanced, and jump-dominant). The technique is based on phase ratio [7] and the improving final speed horizontal ideal for the athlete [6] and condition and not to lose control of the technique and influence in achievement

\section{Conclusion}

From the purposes of this study, we recommend our coaches and their athletes the mean most used in assessment in the triple jump, because the phase ratio allows us not only to measure the effort distribution in 


\section{Jump and Their Relationships with the Finale Results}

the triple jump but also define the techniques and errors of practice. The comparisons guide us to determine the technique practiced and weaknesses of our elites in practice.

Our results and recommendations:

1. All the samples practice the Russian technique as model in the distribution of the phase ratio.

2. The problem of our elites is in the hop phase distribution and its relationship with other phases.

3. Improve achieve horizontal vertical velocity in hop phase as solution.

Our aims:

For the national elites and their technical steps:

Using the biomechanics to determine the errors practice in models theoretical.

Integrated the modern scientific methods into the program monitoring sports.

Respect the modality distribution of efforts in Russian technique to improve the performances.

\section{References}

[1] Koski, R. T. 2004. The Sports of Antiquity. From the Fields of Olympia to Roman Arenas. Jyväskylä: Atena Kustannus Oy, 6.

[2] International Association of Atlithics Fedration. 2002. “Triple-Jump-Introduction." IAAF. Accessed January 1, 2015. www.iaaf.org/news/news/triple-jump-introduction.

[3] Algérienne, F. 2014. "Records Athletics Algeria." Accessed April 19, 2014. https://en.wikipedia.org/wiki/Records_d\%27Alg\%C3\%A 9rie_d\%27athl\%C3\%A9tisme

[4] Allen, S. J., King, M. A., and Yeadon, M. R. 2013. "Trade-offs between Horizontal and Vertical Velocities during Triple Jumping and the Effect on Phase
Distances." Journal of Biomechanics 46 (5): 979-83.

[5] Miladinov, O., and Bonov, P. 2004. "Individual Approach in Improving the Technique of Triple Jump for Women." New Studies in Athletics 4 (19): 27-36.

[6] Samuel, J. A. 2009. "Optimisation of Performance in the Triple Jump Using Computer Simulation.” Ph.D. thesis, Loughborough University, 2.

[7] Hui, L. 2012. "Effects of Phase Ratio and Velocity Conversion Coefficient on the Performance of the Triple Jump.” Journal of Sports Sciences 30 (14): 36.

[8] Nelia, A. M., Tania, F. P. M., and Joao, P. B. 2005. "Approach Speed and Performance in the Horizontal Jumps." IAAF 20 (3): 43-8.

[9] Bing, Y. 1982. "Biomechanics of Triple Jump." Ph.D. thesis, Center for Human Movement Science, The University of North Carolina at Chapel Hill, USA.

[10] Project by the German Atletecs. 2009. Biomechanics Report WC Berlin 2009 Triple Jump. German Atletecs Federration, German.

[11] Ahcenne, A., and Zerf, M. 2015. "A Study of Some Mechanical Focal Stages in the Triple Jump and Their Relationship with Performance." Presented at the 1st International Congress of I3SAW, Algeria.

[12] McNab, T. 1968. Triple Jump. London: Amateur Athletic Association London UK.

[13] Irving, S. 2006. "Mechanics of the Jump Approach." Journal Modern Athlete and Practical Coaching: 14.

[14] Jacoby, E. 2009. Winning Jumps and Pole Vault. USA: Human Kinetics, 43.

[15] Paul, B. "Using Quintic Biomechanics to Calculate Centre of Mass." Q4E Case Study 22, UK: Athletics.

[16] Gordon, R., Graham, C., Joseph, H., Gary, K., and Saunders, W. 2004. Research Methods in Biomechanics. USA: Human Kinetics, 92.

[17] Dziewiecki, K., Mazur, Z., and Blajer, W. 2013. "Assessment of External and Internal Loads in the Triple Jump via Invese Dynamics Simulation.” Biol. Sport 2 (2083): 103-9. 